\title{
Spiritual Intelligence in Relation to Mental Health: A Study among Indian Adolescents
}

\author{
Sumita Thakur ${ }^{1}$, Rakesh Parihar ${ }^{2}$, Sumala Kapila ${ }^{3}$, Vijay K Barwal ${ }^{4}$, \\ Saurabh Rattan ${ }^{5}$ \\ ${ }^{1}$ Counsellor, Govt Model High School, Chandigarh \\ ${ }^{2}$ Academic Counsellor, IGNOU Study Centre, Government College, Sanjauli, Shimla \\ ${ }^{3}$ Assistant Professor, Dept of Radiology, IGMC Shimla \\ ${ }^{4}$ Assistant Professor, Dept of Community Medicine, IGMC Shimla \\ ${ }^{5}$ Dist. Immunization Officer, Dist Kangra, Himachal Pradesh, India. \\ Corresponding Author: Saurabh Rattan
}

DOI: https://doi.org/10.52403/ijrr.20220171

\begin{abstract}
The aim of this study was to investigate and throw more light on the spiritual intelligence and mental health of school going adolescents in Chandigarh city in India. The study was designed to find out the relationship between mental health and spiritual intelligence between male and female adolescents and we used a descriptive cross-sectional survey using quantitative investigation as its research design. The population of the present research was the students of various government schools of Chandigarh, India in the age range of 15-17 years and session 2018-2019. A total sample of 100 students was taken (50 male and 50 female). We used Warwick-Edinburgh Mental Wellbeing Scale (WEMWBS) to assess mental health, while Spiritual Intelligence was measured by Spiritual Intelligence Self-Report Inventory (SISRI-24). For data analysis descriptive statistics such as frequencies, means and standard deviations, Independent Sample ttest for gender and bivariate correlations were employed to find out the relationship between mental health and spiritual intelligence. The findings indicate that students with higher spiritual intelligence own better mental health.
\end{abstract}

Keywords: Spiritual intelligence, Mental health, Adolescents

\section{INTRODUCTION}

Adolescents aged between 10-19 years account for more than one fifth of the world's population. In India, this age group forms 21.4 percent of the total population (National Youth policy 2003). This is a critical developmental period characterized by biological, cognitive, and psychosocial changes in young people (Erikson 1968). Adolescents who experience identity confusion-related distress have more school and behavioural problems (Wires et al. 1994), many have a propensity for risk taking behaviours as a result of cognitive immaturity (Steinberg, 2004). These negative experiences prevent adolescents from fulfilling their responsibilities and developmental tasks (Mcknight et al. 2002). As a result, the changes experienced during this period might affect adolescents' mental health. Although theories attempting to explain this phase of life differ in some respect, there is consensus amongst psychologists that this transition from childhood to adulthood is a turbulent time period that affects children both psychologically and physically.

The World Health Organization (2001) defines mental health as a state of well- being in which the individual realizes his or her own abilities, can cope with the normal stresses of life, can work productively and fruitfully, and is able to contribute to his or her community. It is all about emotional well-being: welcoming and 
fearlessly enjoying new experience, being imaginative and flexible about other people and new people, and being curious and willing to learn.

It could be said that mental health is the satisfactory adjustment to various strains of the environment. So mental health is not a precise term, but an intuitively apprehended idea that strives for scientific status while securing an ideology label too. Thus, a sound mental health develops mental stamina and enables a person to face realization of life. (Hales and Hales). Researchers suggest that there are three main indicators of mental health: emotional, psychological, and social well-being. (Ryff \& Keyes, 1995; Ryff, 1989; Keyes, 1998).

On the other hand, Spiritual intelligence is a term used to indicate a spiritual correlate to Intelligence Quotient (IQ) and Emotional Quotient (EQ). It refers to various skills and abilities that empower one to live in harmony with the highest values and move unswervingly towards one's goals of life. Spiritual intelligence is essential for discernment in making spiritual choices that contribute to psychological well-being and overall healthy human development of human beings.

According to Levin and Vanderpool (1992), experiencing spirituality as an intrinsic part of oneself is necessary for being able to apply spiritual principles to one's behavior and lifestyle. Thus, spiritual intelligence is manifested when a person integrates spirituality with the rest of their life, and acts or operates from their spiritual principles. Zohar and Marshall (2000), described that "with spiritual intelligence we can place our actions and our lives in a wider, richer, meaning-giving context, the intelligence with which we can assess that one course of action or one's life-path is more meaningful than another". According to Wolman (2001), "Spiritual intelligence is a human capacity about the meaning of life, and to simultaneously experience the seamless between each of us and the world in which we live."
Though at one time it was believed that the outcome of adolescence was largely dictated by biological, psychological and social factors, it is now growing clear that one's spirituality also influences adolescence (Wagner (1978), (Hurlock 1981, p. 239).

\section{Mental Health}

Mental health is a term which is defined as state of an individual with emotional stability, overall adjustment to the surrounding, appropriate perception of oneself, harmonious functioning of personality, perception of reality and environmental competencies in their life (Gasima Gupta and Sushil Kumar. (2010).

In the present study mental health is indicated by the total score obtained by the students on the Warwick-Edinburgh Mental Well-being Scale (WEMWBS) (University of Warwick and University of Edinburgh, 2006).

\section{Spiritual intelligence}

Spiritual Intelligence (SQ) as defined by Wigglesworth (2006) is "the ability to behave with Wisdom and Compassion, while maintaining inner and outer peace (equanimity), regardless of the circumstances".

It is represented by the total scores obtained by the students on spiritual intelligence scale developed by The Spiritual Intelligence Self-Report Inventory (SISRI-24), (King, 2008; King \&DeCicco, 2009)

\section{Purpose}

Mental health is an important indicator of all round growth and development of students (Nanda, 2010). It is helpful in dealing with stresses and challenges of everyday life. (Raina, 2012). It is more helpful in dealing with circumstances using controlling of our sense.

There is growing evidence that spirituality influences mental health in adults, but such research is lacking in adolescent population. (Wong, Y. J., Rew, 
L., \& Slaikeu, K. D. (2006). Very few studies have been conducted on school students around the world or in India on this topic. This research needs to be strengthened among high and higher secondary school students because they experience a number of physiological, psychological and developmental changes at this transitional stage. Therefore, the education should be so designed that sound mental health could be developed in children. (Gupta, G. and Kumar, S. (2011). Hence this study was planned out with the primary objective of finding out the relationship of Spiritual intelligence to mental health and contribute to the research literature by throwing more light on this realtionship. We sought answers to the following questions: 1) Whether there is significant relationship between Mental health and sprirtual intelligence of adolescents? 2) Is there any significant relationship of mental health between male and female adolescents? 3) Is there any significant relationship of spiritual intelligence between male and female adolescent?

\section{METHOD}

\section{Research design}

The current study was a descriptive cross-sectional survey using quantitative investigation as its research design. We used mental health as the dependent measure (criterion) and independent measure (predictors) was spiritual intelligence, while demographic variable of the study was gender.

\section{Universe and Sampling}

The population of the present research was the students of various government schools of Chandigarh, India in the age range of 15-17 years and session 2018-2019. A total sample of 100 students was taken (50 male and 50 female). Adolescents studying in classes $10^{\text {th }}, 11^{\text {th }}$ and $12^{\text {th }}$ were selected using convenience sampling. Data collection tool was administered to the students in school after taking permission and time from the appropriate authorities.

\section{Tools used for Data Collection}

The following reliable and valid instruments were used to measure respondent's perceptions:

1. Warwick-Edinburgh Mental Well-being Scale (WEMWBS) (University of Warwick and University of Edinburgh, 2006)

2. The Spiritual Intelligence Self-Report Inventory (SISRI-24), (King, 2008; King \& DeCicco, 2009)

\section{Warwick-Edinburgh Mental Well- being Scale (WEMWBS)}

The WEMWBS was developed to enable the monitoring of mental wellbeing in the general population and the evaluation of projects, programmes and policies which aim to improve mental wellbeing. It is a 14 item scale with 5 response categories, summed to provide a single score ranging from 14-70. The items are all worded positively and cover both feeling and functioning aspects of mental wellbeing. WEMWBS aims to measure mental wellbeing itself and not the determinants of mental well-being, which include resilience, skills in relationship, conflict management and problem solving, as well as socioeconomic factors such as poverty, domestic violence, bullying, unemployment, stigma, racism and other forms of social exclusion. It has been translated into a number of languages including Hindi Language and has been validated both psychometrically and qualitatively.

\section{WEMWBS scoring}

WEMWBS is very simple to score. The total score is obtained by summing the score for each of the 14 items. The latter ranges from $1-5$ and the total score from 14-70. Higher scores represent better mental health. 


\section{Presenting the results}

WEMWBS results were presented as a mean score for the population of interest with either a standard deviation or $95 \%$ confidence interval. The latter both provide a measure of variance of the scores in the population studied (either as a whole or for sub-groups within it).

\section{Interpreting the results}

The average population mean is around 51 and that this varies according to the population group studied. The mean score for the population under study can be compared with these provisional population norms to assess whether the level of mental well-being is above or below this level. Differences between the scores of different groups or between the scores of the same group of people at two points in time, for example, before and after an intervention, need to be tested statistically using students t-Test or equivalent to assess how likely the differences are to have arisen by chance.

\section{The Spiritual Intelligence Self-Report Inventory (SISRI-24) \\ Scoring Procedures}

Total Spiritual Intelligence Score:

Sum of all item responses or subscale scores (after accounting for *reverse-coded item). 24 items in total; Range: $0-96$

\section{Factors/Subscales:}

1. Critical Existential Thinking (CET): Sum items 1, 3, 5, 9, 13, 17, and 21. 7 items in total;range: $0-28$

2. Personal Meaning Production (PMP): Sum items 7, 11, 15, 19, and 23. 5 items in total;range: $0-20$

3. Transcendental Awareness (TA): Sum items $2,6^{*}, 10,14,18,20$, and 22.7 items in total;range: $0-28$

4. Conscious State Expansion (CSE): Sum items 4, 8, 12, 16, and 24. 5 items in total;range: 0 - 20

*Reverse Coding: Item \# 6 (response must be reversed prior to summing scores).

Higher scores represent higher levels of spiritual intelligence and/or each capacity.
Permissions for Use: Use of the SISRI is unrestricted so long as it is for academic, educational, or research purposes. Unlimited duplication of this scale is allowed with full author acknowledgement only.

\section{Ethical Considerations}

The study was approved by the Discipline of Psychology, School of Social Sciences, Indira Gandhi National Open university review board vide approval letter dated 25 $5^{\text {th }}$ February 2019 (Enrollment Number 150208909).

\section{Data Analysis}

Descriptive statistics such as frequencies, means and standard deviations, were computed to study the nature and distribution of scores for the variables of the study viz. mental health and spiritual intelligence. Differential analysis using Independent $\mathrm{t}$-test for gender was done to determine if there are any statistical differences in the mean scores of mental health and spiritual intelligence. Bivariate Correlations were employed to find out the relationship between mental health and spiritual intelligence. A $\mathrm{p}$ value of $<0.05$ was taken as significant. Epi info version 7.2.2.2 was used to analyze the data.

RESULTS

Table 1: Demographic profile of students $(\mathrm{N}=100)$

\begin{tabular}{|c|c|c|c|}
\hline $\begin{array}{l}\text { S.I. } \\
\text { No. }\end{array}$ & Variables & Categories & Percentage \\
\hline \multirow[t]{2}{*}{1.} & \multirow[t]{2}{*}{ Age of student } & $15-16$ & $45 \%$ \\
\hline & & $16-17$ & $55 \%$ \\
\hline \multirow[t]{2}{*}{2.} & \multirow{2}{*}{$\begin{array}{l}\text { Educational } \\
\text { Level of Mother }\end{array}$} & Under Graduate & $80 \%$ \\
\hline & & Graduate and above & $20 \%$ \\
\hline \multirow[t]{4}{*}{3.} & \multirow[t]{4}{*}{ Castes of student } & General & $44 \%$ \\
\hline & & $\begin{array}{l}\text { Other Backward } \\
\text { Classes (OBC) }\end{array}$ & $25 \%$ \\
\hline & & Schedule Cast (SC) & $19 \%$ \\
\hline & & Schedule Tribe (ST) & $12 \%$ \\
\hline \multirow[t]{4}{*}{4.} & \multirow{4}{*}{$\begin{array}{l}\text { Religion } \\
\text { student }\end{array}$} & Hindus & $74 \%$ \\
\hline & & Sikhs & $20 \%$ \\
\hline & & Muslims & $4 \%$ \\
\hline & & Christians & $2 \%$ \\
\hline \multirow[t]{3}{*}{5.} & Type of Family & Nuclear & $78 \%$ \\
\hline & & Joint & $12 \%$ \\
\hline & & Extended & $10 \%$ \\
\hline \multirow[t]{2}{*}{6.} & \multirow{2}{*}{$\begin{array}{l}\text { Educational level } \\
\text { of Father }\end{array}$} & Under Graduate & $55 \%$ \\
\hline & & Graduate and above & $45 \%$ \\
\hline
\end{tabular}

\section{RESULTS}

45 percent of the students were in the age group of 15-16 years while the rest were in the 16-17 years age group. 
The level of education of majority of students' mothers was below graduation i.e. $80 \%$. The rest $20 \%$ mothers were educated up to graduate or postgraduate level. While $45 \%$ fathers were graduate or above, the rest were educated only up to the undergraduate level. If we see the social class of students, $44 \%$ belonged to the general category, $25 \%$ were from OBC, followed by $19 \%$ schedule caste and Schedule tribe constituted the remainder $12 \%$. As far as religion is concerned, majority of the students $(74 \%)$ belonged to Hindu religion, followed by $20 \%$ Sikhs, $4 \%$ Muslims and 2\% Christians. Also with regards to the type of family, majority of the students (78\%) belonged to a nuclear family, just $12 \%$ had a joint family and $10 \%$ were having an extended type of family.

Table 2. Relationship between mental health and spiritual intelligence.

\begin{tabular}{|l|l|l|l|l|}
\hline Variable & $\mathbf{N}$ & Df & $\begin{array}{l}\text { Calculated } \\
\text { value of 'r' }\end{array}$ & $\begin{array}{l}\text { Level of } \\
\text { significance (p) }\end{array}$ \\
\hline Mental health & 100 & 98 & 0.43 & $<0.05$ \\
\cline { 1 - 2 } $\begin{array}{l}\text { Spiritual } \\
\text { Intelligence }\end{array}$ & & & & \\
\hline
\end{tabular}

\section{INTERPRETATION}

It is inferred that there is a positive significant statistical relationship at $(0.05$ level of significance) between mental health and spiritual intelligence among school students. (Table 2) It indicates the existence of positive statistical linking relationship between mental health and spiritual intelligence among school students in Chandigarh. The calculated $r$ value for quality of mental health and spiritual intelligence among school students is 0.43 . It means that in our study there exists a significant relationship between mental health and spiritual intelligence of the adolescents.

Table 3. Relationship between mental health and spiritual intelligence of students dimension wise.

\begin{tabular}{|l|l|}
\hline Dimension & Coefficient of correlation \\
\hline Critical Existential Thinking (CET) & 0.40 \\
\hline $\begin{array}{l}\text { Personal Meaning Production } \\
\text { (PMP) }\end{array}$ & 0.38 \\
\hline Transcendental Awareness(TA) & 0.31 \\
\hline Conscious State Expansion (CSE) & 0.31 \\
\hline
\end{tabular}

Table 3 shows the coefficient of correlation between various dimensions of mental health and spiritual intelligence of the students. Here we find that the dimensions like Critical Existential Thinking (CET, Personal Meaning Production (PMP), Transcendental Awareness (TA), Conscious State Expansion (CSE) are significantly related with the mental health of school students.

$\mathrm{H} 2$ : There is no significant gender difference on mental health.

The differential analysis provides inference involving determination of statistical significance of difference between categories with reference to the selected variables. In the present investigation the investigator applied t-test.

TABLE 4: Comparative Mean Scores Of Mental Health Of Boys And Girls Of School Students

\begin{tabular}{|l|l|l|l|l|l|}
\hline Gender & N & Mean & SD & t & df \\
\hline Male & 50 & 53.40 & 5.767 & 3.596 & 98 \\
\cline { 1 - 4 } Female & 50 & 57.43 & 6.01 & & \\
\hline
\end{tabular}

From the Table 4 the mean and standard deviation of male with respect to mental health is 53.40 and 57.30. Further, the mean of girls is 57.30 and Standard deviation is 6.01. It is found that the obtained value of $t$ (3.596) at 98 degree of freedom is higher than the table value of ' $t$ ' at 0.05 (1.96) level of significance. Since the computed value of ' $t$ ' is higher than the table value of ' $t$ ' at 5 percent of significance level. Thus, the hypothesis 2 which is read as "There is no significant gender difference on mental health" is rejected.

According to Table 5.2 girls have higher level of mental health than boys. This may be because, in Indian tradition the girls are trained to be tolerant, adjusting. So they try to get adjusted and live in reality. Whereas boys are provided with whatever they want and not trained to be adjusting, therefore the girls may have higher level of mental health.

\section{H3: There is no significant gender differences on spiritual intelligence.}


TABLE 5: Comparative Mean Scores Of Spiritual Intelligence Of Boys And Girls

\begin{tabular}{|l|l|l|l|l|l|}
\hline Gender & N & Mean & SD & t & Df \\
\hline Male & 50 & 76.58 & 8.192 & 3.452 & 198 \\
\cline { 1 - 4 } Female & 50 & 82.31 & 7.145 & & \\
\hline
\end{tabular}

Table 5 represents the mean scores of spiritual intelligence according to their gender. Out of a maximum score of 96 the mean scores for males was $22.58 \pm 8.192$ while it was $24.31 \pm 7.145$ for female students. This higher mean score of female students with respect to the male students was found to be statistically significant as well. Thus, the hypothesis 3 which is read as "There is no significant gender difference in spiritual intelligence of school students" is rejected.

Out of a maximum score of 70 the mean scores for males was 53.40 \pm 5.67 while it was $57.43 \pm 6.01$ for female students. Hence the female scores were higher than the male students and this was statistically significant as well.

Scores of spiritual intelligence of females was significantly higher than that of males.

This may be attributed to the Indian child rearing practices wherein the girls are asked to adjust, control their emotions which would result in their emotional maturity. It is that part of the individual that enables a person to see the consequences of his/her action, create a purpose for their lives, change boundaries, ask "why" the particular rule and create the possibility of having meaning in their lives.

In present study significant and positive correlation was found between mental health and spiritual intelligence of students. The study reveals that there exists gender difference at the level of mental health and spiritual intelligence of students. This is in context with the previous studies conducted by Nazam (2014) on gender difference on spiritual intelligence among adolescents. The aim of the research was to measure spiritual intelligence among adolescents studying in two schools of Aligarh city. For this purpose, Spiritual Intelligence Self Report Inventory (SISRI-
24) developed by D. King (2008) was administered to the sample of 60 adolescents. Of these, 30 were male and 30 were female students. The main findings were as follows: Significant difference were found between the two groups, on subscales, namely, Personal Meaning Production (PMP), Transcendental Awareness (TA) and Conscious State Expansion (CSE), Critical Existential Thinking (CET) and composite scores on spiritual intelligence

\section{MAJOR FINDINGS}

- It indicates the existence of positive statistical linking relationship between mental health and spiritual intelligence among school students in Chandigarh. The calculated $r$ value for quality of mental health and spiritual intelligence among school students is 0.43 . It means the Hypothesis 1 which stated as No relationship exists between mental health and spiritual intelligence of adolescents in case of total sample is rejected and an alternate hypothesis is accepted which read as Significant relationship exists between mental health and spiritual intelligence of adolescents in case of total sample.

- Mean and standard deviation of male with respect to mental health is 53.40 and 57.30. Further, the mean of girls is 57.30 and Standard deviation is 6.01. It is found that the obtained value of $t$ (3.596) at 98 degree of freedom is higher than the table value of ' $t$ ' at 0.05 (1.96) level of significance.

- The mean and standard deviation of male with respect to spiritual intelligence is 24.31 and 7.145. Further, the mean of girls is 22.58 and Standard deviation is 8.192. It is found that the obtained value of $t$ (3.452) at 98 degree of freedom is higher than the table value of ' $t$ ' at 0.05 (1.96) level of significance. Since the computed value of ' $t$ ' is higher than the table value of ' $t$ ' at 5 percent of significance level. 


\section{DISCUSSION}

Spiritual intelligence represents a set of spiritual capabilities, abilities and resources that its employment leads to increasing adaptability and as a result, mental health in students (King, 2008; Zohar and Marshall, 2000). When we mention spiritual intelligence, it means a kind of intelligence that solves our semantic problems, signifies our activities and life at a wider and stronger level and someone's meaning of life and life path can be measured by it (Emmons, 2000). Spiritual intelligence is an improved and more efficient version of intellectual intelligence and emotional intelligence (Zohar and Marshall, 2000). According to Vaughan (2002), spiritual intelligence integrates inner and spiritual life with outer life and work environment. Spiritual experience, which may be effective in the development of spiritual intelligence, depends on one's living environment and texture. According to Vaughan, spiritual intelligence is necessary for identifying choices that play important roles in human being's psychological well-being and health. Spiritual intelligence leads to a new insight into self and increasing self-confidence. It also helps to own a stable self, increase anxiety and concerns and communicate with others more deeply (King, 2008). The results are in harmony with the findings of Akbarizadeh et al. (2012), Goudarzi et al. (2010), Mitchell et al. (2006), Walt and Alletta (2006), Wang (2010) and Yang (2006). Regarding the limitations of the study, it was a convenience sampling, so we have to be careful in generalizing the findings. Though regression analysis would have been most appropriate, but owing to a small sample size we could not go beyond univariate analysis. This study was intended to form a basis for a similar study with a larger sample group.

\section{CONCLUSION}

- The results demonstrate that spiritual intelligence and its dimensions including personal meaning-creation, transcendental awareness, development of self-awareness and existential critical thinking have significant and positive effect on mental health of the students of Chandigarh city. Therefore, students with higher spiritual intelligence own a better mental health. In fact, spiritual intelligence plays an important role in strengthening and improving mental health in adolescents by way of creating and strengthening capabilities such as flexibility, high level of self-awareness, adaptive applications, tranquility creation, etc.

\section{Suggestions For Further Research Study}

- The similar study can be conducted on students of different age group.

- A study can be under taken to develop package for developing mental health and spiritual intelligence among secondary school students.

- The curriculum of secondary school can be analyzed in the background of learning experience provided to later to mental health and spiritual intelligence of students.

- Mental health and spiritual intelligence of secondary school students can be studied in relation to their socioeconomic status.

- The study can be conducted to assess the level of mental health among teachers teaching at different levels.

\section{Acknowledgement: None}

Conflict of Interest: None

\section{Source of Funding: None}

\section{Ethical Approval: Approved}

\section{REFERENCES}

1. Akbarizadeh F, Bagheri F, Hatami HR, Hajivandi A. [Relationship between nurses' spiritual intelligence with hardiness and general health]. Behbood. 2012;15(6):46672. Persian. 
2. Bartwal, RS (2014). To study the mental health of senior secondary students in relation to their emotional intelligence. The International Journal of Humanities \& Social Studies, 19(2), 6-10.

3. Emmons, R. A. (2000). Is Spirituality an Intelligence? Motivation, Cognition, and the Psychology of Ultimate Concern. Int $J$ Psychol Relig. The International Journal for the Psychology of Religion, 10:1, 326, DOI: 10.1207/S15327582IJPR1001_2

4. Erikson, E. (1968). Identity: Youth and crisis. New York: Norton.

5. Gasima Gupta and Sushilkumar.(2010). Mental health in relation to emotional intelligence and self efficacy among college students. Kurukshetra university, Kurukshetra. Journal of the Indian Academy of applied psychology, January 2010, Vol.36, No.1, pp-61-67.

6. Goudarzi K, Sohrabi F, Farrokhi NA, Jamhari F. Interactive effects of spiritual intelligence and life skills training on students' mental health. Clini Psychol Stud. 2010;1(1):15-41.

7. Hales, D., \& Hales, R. E. (1995). Caring for the Mind: The Comprehensive Guide to Mental Health. New York: Bantam Books.

8. Hurlock E.B. (1981), Developmental Psychology. A life-span approach, $5^{\text {th }}$ edition, published by- Tata McGraw New Delhi, pp-389.

9. Keyes, C.L.M. (1998). Social well-being. Soc Psychol Quart ,61:121-140.

10. King, DB (2008). Rethinking claims of spiritual intelligence: A definition, model, and measure. Unpublished master thesis. Ontorio Canada: Trent University.

11. King, D.B., \& DeCicco, T.L. (2009). A Viable Model and Self-Report Measure of Spiritual Intelligence. International Journal of Transpersonal Studies, 28:68-85

12. Levin, J., \& Vanderpool, H. (1992). Religious factors in physical health and the prevention of illness. In K. Pargament, $\mathrm{K}$. Maton, \& R. Hess (Eds.), Religion and prevention in mental health: Research, vision, and action. (pp. 41-64). New York, NY: Haworth Press.

13. Mcknight, C. G., Huebner, E. S., \& Suldo, S. (2002). Relationships among stressful life events, temperament, problem behaviour, and global life satisfaction in adolescents. Psychology in the Schools, 39, 677-687.
14. Mitchell, D. L., Bennett, M. J. and ManfrinLedet, L. (2006). Spiritual development of nursing students: developing competence to provide spiritual care to patients at the end of life. J Nurs Educ, 45(9), 365-70.

15. Nanda, A.K. (2001), in Mental Health of High School Students: A Comparative Study; Indian Psychological Review, 56(1), 2-7.

16. Ryff, C.D. \& Keyes, C.L.M. (1995). The structure of psychological well-being revisited. J Pers Soc Psychol, 69:719-727.

17. Ryff, C.D.(1989). Happiness is everything, or is it? Explorations on the meaning of psychological well-being. $J$ Pers Soc Psychol ,57:1069-1081

18. Steinberg, L. (2004). Risk-taking in adolescence: What changes, and why? Annals of the New York Academy of Sciences, 1021, 51-58.

19. Tennant, R., Hiller, L., Fishwick, R., Platt, S., Joseph, S., Weich, S., Parkinson, J., Secker, J., \& Stewart-Brown, S. (2007). The Warwick-Edinburgh Mental Well-being Scale (WEMWBS): development and UK validation. Health and quality of life outcomes, 5 , https://doi.org/10.1186/1477-7525-5-63

20. Vaughan, F. (2002). What is spiritual intelligence? Journal of Humanistic Psychology, 42(2), 16- 33.

21. Wagner PC, Stedman R, Brown HOJ, Rudin AJ, Reinhard JA, Kantzer KS. Christianity Today, Volume XXII Number 20, August 18, 1978| Jan 1, 1978.

22. Walt, V. and Alletta, E. (2006). A descriptive and exploratory study towards a spiritual intelligent transitional Model of organizational communication University of South Africa. J Nurs Res, 35(2), 273-80

23. Wigglesworth, C (2006). Why Spiritual Intelligence is Essential to Mature Leadership, Integral Leadership Review VI(3).

24. Wires, J. W., Barocas, R., \& Hollenbeck, A. R. (1994). Determinants of adolescent identity development: A cross-sequential study of boarding school boys. Adolescence, 29(114), 361-378.

25. Wolman, R. (2001). Thinking with your soul: Spiritual intelligence and why it matters. New York: Harmony.

26. Wong, Y. J., Rew, L., \& Slaikeu, K. D. (2006). A systematic review of recent research on adolescent 
religiosity/spirituality and mental health. Issues in mental health nursing, 27(2), 161-183. https://doi.org/10.1080/0161284050043694 1)

27. Yang K. P. (2006). The spiritual intelligence of nurses in Taiwan. The journal of nursing research: $\quad J N R, 14(1), \quad 24-35$. https://doi.org/10.1097/01.jnr.0000387559.2 $6694.0 \mathrm{~b}$
28. Zohar, D., \& Marshall, I. (2000). SQ: Connecting with our spiritual intelligence. New York: Bloomsbury

How to cite this article: Thakur S, Parihar R, Kapila $S$ et.al. Spiritual intelligence in relation to mental health: a study among Indian adolescents. International Journal of Research and Review. 2022; 9(1): 614-622. DOI: https:// doi.org/10.52403/ijrr.20220171 